Louisiana State University

LSU Digital Commons

6-1-2012

\title{
Tools for the identification of bioactives impacting the metabolic syndrome: Screening of a botanical extract library using subcutaneous and visceral human adipose-derived stem cell- based assays
}

\author{
Benjamin M. Buehrer \\ Zen-Bio, Inc. \\ David J. Duffin \\ Zen-Bio, Inc. \\ Y. Renee Lea-Currie \\ Zen-Bio, Inc. \\ David Ribnicky \\ School of Environmental and Biological Sciences \\ Ilya Raskin \\ School of Environmental and Biological Sciences
}

See next page for additional authors

Follow this and additional works at: https://digitalcommons.Isu.edu/biosci_pubs

\section{Recommended Citation}

Buehrer, B., Duffin, D., Lea-Currie, Y., Ribnicky, D., Raskin, I., Stephens, J., Cefalu, W., \& Gimble, J. (2012).

Tools for the identification of bioactives impacting the metabolic syndrome: Screening of a botanical extract library using subcutaneous and visceral human adipose-derived stem cell-based assays. Journal of Nutritional Biochemistry, 23 (6), 519-525. https://doi.org/10.1016/j.jnutbio.2011.02.005 


\section{Authors}

Benjamin M. Buehrer, David J. Duffin, Y. Renee Lea-Currie, David Ribnicky, llya Raskin, Jacqueline M. Stephens, William T. Cefalu, and Jeffrey M. Gimble 


\title{
Tools for the identification of bioactives impacting the metabolic syndrome: Screening of a botanical extract library using subcutaneous and visceral human adipose-derived stem cell based assays
}

\author{
Benjamin M. Buehrera, David J. Duffin ${ }^{a}$, Y. Renee Lea-Currie ${ }^{a}$, David Ribnicky ${ }^{b}$, llya \\ Raskin $^{b}$, Jacqueline M. Stephens ${ }^{c}$, William T. Cefalu ${ }^{d,}$, and Jeffrey M. Gimble ${ }^{e}$ \\ a Zen-Bio, Inc., Research Triangle Park, NC 27709 \\ ${ }^{b}$ Department of Plant Biology and Pathology, School of Environmental and Biological Sciences, \\ Rutgers University, New Brunswick, NJ 08901 \\ c Department of Biological Sciences, Louisiana State University, Baton Rouge, LA70803 \\ d Diabetes and Nutrition Research Laboratories, Pennington Biomedical Research Center, Baton \\ Rouge, LA 70808 \\ e Stem Cell Biology Laboratory, Pennington Biomedical Research Center, Baton Rouge, LA \\ 70808
}

\begin{abstract}
Plant extracts continue to represent an untapped source of renewable therapeutic compounds for the treatment and prevention of illnesses including chronic metabolic disorders. With the increase in worldwide obesity and its related morbidities, the need for identifying safe and effective treatments is also rising. As such, use of primary human adipose-derived stem cells represents a physiologically relevant cell system to screen for bioactive agents in the prevention and treatment of obesity and its related complications. By using these cells in a primary screen, the risk and cost of identifying artifacts due to interspecies variation and immortalized cell lines is eliminated. We demonstrate that these cells can be formatted into 384-well high throughput screens to rapidly identify botanical extracts that affect lipogenesis and lipolysis. Additionally, counterscreening with human primary stem cells from distinct adipose depots can be routinely performed to identify tissue specific responses. In our study, over 500 botanical extracts were screened and $16(2.7 \%)$ were found to affect lipogenesis and $4(0.7 \%)$ affected lipolysis.
\end{abstract}

\section{Keywords}

Adipogenesis; Adipose-derived Stem Cells; Botanical Extracts; Lipogenesis; Lipolysis; Subcutaneous; Visceral

\footnotetext{
(C) 2011 Elsevier Inc. All rights reserved.

*Corresponding Author: William T. Cefalu, MD, Director, Botanical Research Center, Pennington Biomedical Research Center, 6400 Perkins Rd, Baton Rouge, LA 70808.

Publisher's Disclaimer: This is a PDF file of an unedited manuscript that has been accepted for publication. As a service to our customers we are providing this early version of the manuscript. The manuscript will undergo copyediting, typesetting, and review of the resulting proof before it is published in its final citable form. Please note that during the production process errors may be discovered which could affect the content, and all legal disclaimers that apply to the journal pertain.
} 


\section{Introduction}

The prevalence of obesity, metabolic syndrome, diabetes, and their associated comorbidities have increased significantly across the world over the recent past. As such, it is imperative we implement successful and viable strategies in order to address the global epidemic. In this regard, and in an historical perspective, extracts from plants, i.e. botanicals, have proven to be a rich resource for the discovery of therapeutic compounds and the sources of many current medicinal drugs. Throughout the world, traditional cultures have identified specific plant species for the treatment of multiple disorders, including the metabolic syndrome and diabetes. In particular, plant extracts proposed to contain effective "bioactives" are marketed routinely as therapeutic agents for metabolic syndrome and diabetes, often with limited understanding of mechanism or proof of efficacy. Recently, the World Health Organization and the NIH have supported international efforts to develop comprehensive libraries of botanical extracts for therapeutic drug discovery. Studies have begun to screen these libraries for candidate molecules directed towards the prevention and treatment of the metabolic syndrome using cell based in vitro assays.

Given the importance of insulin resistance in peripheral tissues such as adipose tissue and muscle in the etiology of metabolic syndrome and progression to Type 2 diabetes, both adipocyte and skeletal muscle cell lines have been employed in these studies. In most analyses of adipocytes, investigators have chosen to use the 3T3-L1 murine pre-adipocyte cell line. This in vitro model of adipogenesis is characterized by a homogeneous morphology and a robust lipogenic and lipolytic response to known agonists and antagonists. However, since the 3T3-L1 cell line is of murine origin, its utility as a drug discovery tool for eventual human conditions has been questioned due to inter-species variations. A number of laboratories, including those in the pharmaceutical industry, have begun to employ primary human adipose-derived stromal/stem cells (ASCs) as an alternative in vitro model for adipocyte differentiation and function. The ASC can be derived from many adipose depots in human subjects, including subcutaneous and omental/ visceral tissue. There is a growing body of literature indicating that the metabolic function and drug response of adipocytes in these depots is distinct. This has potential implications with respect to the pathology, diagnosis, and treatment of metabolic syndrome and diabetes for the human condition. The current study reports the use of both primary human subcutaneous- and visceral-derived ASCs to screen a library of botanical extracts for both lipogenic and lipolytic agonists and antagonists. These preliminary studies have the potential to yield novel pharmaceuticals of plant origin for the treatment or prevention of metabolic syndrome.

\section{Materials and methods}

\subsection{Chemicals}

2.1.1. Botanical Extract Library-The source of plant extracts were prepared and obtained from the John S. McIlhenny Laboratory of Botanical Research as part of the NIH funded Center for the study of Botanicals and Metabolic Syndrome. The extracts were originally obtained as part of the International Cooperative Biodiversity Group (ICBG) program. Field-collected plant samples were prepared by air drying and extraction with $80 \%$ ethanol $(1: 5 \mathrm{w} / \mathrm{v})$ three times, infused each time for $24 \mathrm{~h}$ and evaporated in a rotary evaporator. The obtained extracts were dried under vacuum and stored in amber glass vials at $-20^{\circ} \mathrm{C}$. The yield of air dried extract as the percent weight of the dried plant tissue varied among the tested samples based on the plant part used. Before tests, concentrates were dissolved by sonication in DMSO for a final concentration of $20 \mathrm{mg} / \mathrm{mL}$. 
2.1.2. Chemicals and reagents-Type I collagenase was obtained from Worthington Biochemical (Lakewood, NJ). Bovine serum albumin (BSA), dexamethasone, biotin, pantothenate, isoproterenol, and isobutyl methylxanthine (IBMX) were purchased from Sigma (St Louis, MO). Human recombinant insulin was obtained from MP Biomedicals (Solon, $\mathrm{OH}$ ). The fetal bovine serum, Dulbecco modified Eagle's medium (DMEM), phosphate-buffered saline (PBS), and Ham's F-12 nutrient broth were from Zen-Bio (RTP, NC). Tumor Necrosis Factor alpha was from Roche Diagnostics (Indianapolis, IN). All tissue culture flasks and plates were obtained from Corning (Corning, NY).

\subsection{Preparation and culture of primary ASC from subcutaneous and visceral depots} 2.2.1. Isolation of human primary ASCs from subcutaneous and omental depots-Human adipose tissue samples were procured from consenting donors undergoing elective surgeries under IRB approved protocols. Subcutaneous and omental adipose tissue was from surgical waste material derived from subcutaneous lipoaspirate or omentum tissue.

Human ASCs were isolated from lipoaspirate or omental waste tissue as previously described. Adipose tissue was extensively washed with PBS prior to processing. Omental tissue samples were hand-minced while washed lipoaspirate material was directly transferred for dissolution with an equal volume of Krebs Ringer buffer containing $0.1 \%$ collagenase and $1 \%$ BSA. Following a $15-45$ minute incubation at $37{ }^{\circ} \mathrm{C}$, floating primary adipocytes and most of the collagenase buffer were removed and PBS was added. The remaining stromal vascular cell suspension was subjected to centrifugation for 5 minutes at $300 \times \mathrm{g}$ and the resulting cell pellet washed several times with PBS. Finally the cell pellet was suspended in preadipocyte medium (PM-1, Zen-Bio) and plated in a culture flask for expansion. ASCs were subcultured prior to reaching confluence and plated at a density of 1.4 million cells per T-225 flask $\left(6,300\right.$ cells $\left./ \mathrm{cm}^{2}\right)$ for further expansion in PM-1 containing epidermal growth factor (EGF) and fibroblast growth factor (FGF).

2.2.2. Preparation of subcutaneous and omental ASC super-lots-Mixed patient lots of either subcutaneous or omental ASCs were prepared from cryopreserved ASCs derived from 4-6 donor lots each. The subcutaneous super-lot was derived from 6 female donors with an average age of $40 \pm 3.3$ (S.E.) and average BMI of $27.9 \pm 0.6$. The omental super-lot was derived from 4 female donors with an average age of $40 \pm 3.8$ (S.E.) and average BMI of $45.6 \pm 4.9$. Equal numbers of passage 1 ASCs were combined in preadipocyte medium and plated for expansion at a density of 2.2 million cells per chamber (3,500 cells $\left./ \mathrm{cm}^{2}\right)$ in CellSTACK chambers (Corning). The super-lot cells were expanded to near confluence and harvested by trypsinization for cryopreservation and later use.

To ensure the quality of the prepared cell super-lots, both the omental and subcutaneous lots were tested for differentiation and lipolytic response. Both lots met the required cutoff values for triglyceride accumulation and free fatty acid (FFA) release under standard differentiation procedures. Cell surface markers for both lots of ASCs were confirmed using flow cytometry and antibodies to positive markers (CD29, CD44, and CD105) and negative markers (CD14, CD31, and CD45).

\subsection{Screen botanical extracts for human adipocyte lipolysis}

Mature adipocytes in clear bottom 384-well plates were prepared by seeding ASCs at a density of 6,000 cells/well and differentiating them to adipocytes by adding differentiation medium (DM-2, Zen-Bio) for 7 days. After differentiation, the medium was partially replaced with adipocyte medium (AM-1, Zen-Bio) and the cells incubated for a further 7 days at $37{ }^{\circ} \mathrm{C}$ with $5 \% \mathrm{CO}_{2}$. This procedure results in greater than $80 \%$ adipocyte differentiation. Medium was aspirated and the cells washed twice with $50 \mu 1$ PBS using a 
cell washer (ELx-405 Select CW, BioTek) prior to adding $25 \mu \mathrm{l}$ of assay buffer to each well. Botanical extracts were diluted in a two step process by using a Matrix PlateMate $2 \times 3$ (ThermoScientific), first a 50-fold dilution into assay buffer was performed, followed by a similar 10-fold dilution. $25 \mu \mathrm{l}$ of the 500 -fold dilutions were added to the assay plates in quadruplicate for a final dilution of 1000 -fold $(20 \mu \mathrm{g} / \mathrm{ml})$. Isoproterenol $(100 \mathrm{nM})$ and DMSO $(0.1 \%)$ were added to quadruplicate wells on every plate and served as the positive and negative controls, respectively. Cells and extracts were incubated for 4 hours at $37{ }^{\circ} \mathrm{C}$ with $5 \% \mathrm{CO}_{2}$ to accumulate free fatty acid in the conditioned assay buffer.

For follow-up experiments in 96-well plates, preadipocytes were seeded at a density of 13,000 cells/well and differentiated as described above. Cells were washed twice with PBS and treated with extracts in a final volume of $100 \mu \mathrm{l}$ of assay buffer for 4 hours.

2.3.1. Measuring fatty acid release in human cultured adipocytes-Free fatty acids released into the conditioned assay buffer were quantified using Lipolysis Assay Kit reagents (Zen-Bio, Inc.). For the initial screen, $15 \mu \mathrm{l}$ of conditioned assay buffer was removed from each well and transferred to new 384-well plate for determination of fatty acid release. $50 \mu \mathrm{l}$ of FFA solution A was added to $15 \mu \mathrm{l}$ of conditioned assay buffer and incubated at $37^{\circ} \mathrm{C}$ for 10 minutes. $25 \mu \mathrm{l}$ of FFA solution B was added to each well and incubated for an additional 10 minutes at $37{ }^{\circ} \mathrm{C}$. Total Free fatty acids released were determined by measuring the optical density at $540 \mathrm{~nm}$ and comparison to a standard curve ranging from 1.5 to $333 \mu \mathrm{M}$. Quadruplicate values were averaged and standard deviations were used to determine statistical differences between controls. Follow up assays were performed in 96-well plates essentially as described but with $30 \mu \mathrm{l}$ of conditioned assay buffer, $100 \mu \mathrm{l}$ FFA solution A and $50 \mu$ l FFA solution B.

To determine if positive values resulted from extract interference with the assay reagents, we performed fatty acid assays using extracts diluted into assay buffer without exposure to cells. If the resulting value was above $10 \mu \mathrm{M}$, it was concluded that the extract interfered with the assay.

\subsection{Screen botanical extracts for lipogenic effects in human adipocytes}

ASCs were seeded at 6,000 cells/well in clear bottom 384-well plates using PM-1. The next day a $40 \%$ mixture of DM-2 and PM- 1 was added and incubated for 7 days at $37{ }^{\circ} \mathrm{C}$ with $5 \% \mathrm{CO}_{2} .4$ wells were given $100 \%$ DM-2 to serve as a positive control. An additional 4 wells were given PM-1 to serve as an uninduced control. Botanical extracts were added on day 7 through a two step dilution process in AM-1 to give a $50 \mu \mathrm{g} / \mathrm{ml}$ final concentration. $0.25 \%$ DMSO was added to 4 wells to serve as a vehicle control and $10 \mathrm{ng} / \mathrm{ml} \mathrm{TNFa}$ served as a positive control of inhibition. The cells and extracts were incubated at $37{ }^{\circ} \mathrm{C}$ with $5 \%$ $\mathrm{CO}_{2}$ for an additional 7 days prior to quantifying total accumulate triglyceride.

\subsubsection{Triglyceride measurement in subcutaneous and omental adipocytes-}

The total accumulated triglyceride was determined using Total Triglyceride Kit reagents (Zen-Bio, Inc.). The medium was aspirated and the cells were washed once with $50 \mu \mathrm{l}$ Wash Buffer using an automated cell washer (BioTek). $5 \mu$ of Lysis Buffer was added to each well and cells were incubated at $37^{\circ} \mathrm{C}$ for 20 minutes to complete the cellular lysis. $45 \mu \mathrm{l}$ of Wash Buffer was added to each well before adding $6.7 \mu l$ Reagent B (lipase) and incubating for an additional 2 hours at $37^{\circ} \mathrm{C} .12 .5 \mu \mathrm{l}$ of each lipase treated sample was transferred to a new 384-well plate containing $12.5 \mu \mathrm{l}$ Wash Buffer. An equal volume of Glycerol Reagent A $(25 \mu \mathrm{l})$ was added to each well and incubated for 15 minutes at room temperature.

Glycerol content was determined by measuring the optical density at $540 \mathrm{~nm}$ and comparing 
the values to a glycerol standard curve. There is a 1:1 molar ratio between the amount of glycerol detected and cellular triglyceride content.

Treatments and assays performed in 96-well plates followed a similar protocol, but the volumes were adjusted for the larger plate format. Preadipocytes were seeded at 13,000 cells per well prior to differentiation and extract treatment in $150 \mu \mathrm{l}$ final volume. Volumes were changed to $15 \mu \mathrm{l}$ Lysis buffer, $135 \mu \mathrm{l}$ Wash buffer and $20 \mu \mathrm{l}$ of Reagent B. $10 \mu l$ of each sample was diluted into $40 \mu \mathrm{l}$ of Wash buffer and $50 \mu \mathrm{l}$ of Reagent A added to initiate quantification of glycerol.

\subsection{Cytotoxicity analysis of botanical extracts}

Extract induced cytotoxicity was assessed in the 384-well format using conditions for the lipogenic assay. Instead of performing the triglyceride assay, $25 \mu \mathrm{l}$ of conditioned medium was removed and $5 \mu \mathrm{l}$ of Cell Titer Blue reagent (Promega) added to each well. Cells and reagent were incubated at $37{ }^{\circ} \mathrm{C}$ in a humidified $5 \% \mathrm{CO}_{2}$ incubator for 2 hours. The absorbance a $570 \mathrm{~nm}$ was measured for each well and that from the reference wavelength $(600 \mathrm{~nm})$ subtracted. The background value $\left(\mathrm{OD}_{570}-\mathrm{OD}_{600}\right)$ from wells without cells was subtracted from each value to determine the extract induced change in absorbance. Cytotoxicity was reflected by a decrease in the $\left(\mathrm{OD}_{570}-\mathrm{OD}_{600}\right)$ absorbance value. $0.1 \%$ Triton X-100 served as a positive control for cytotoxicity.

\subsection{Statistics}

For the screen results, quadruplicate values were averaged and the standard deviation for each treatment determined. Values are displayed based on total cell number seeded per well. Significant differences from control values were determined using a paired Student's t-test with $\mathrm{p} \leq 0.05$ cutoff. Cutoff values for an active extract identified in the primary screen were established based on being more than 3 standard deviations from the control mean. The screening statistic, $Z^{\prime}$, was determined for each assay according to Zhang et al based on the means and standard deviations of the positive and negative controls using the following equation: $Z^{\prime}=1-\frac{3 *(S D 1+S D 2)}{|\mu 1-\mu 2|}$, where SD1 is positive control standard deviation; SD2 is negative control standard deviation; $\mu 1$ is positive control mean; $\mu 2$ is negative control mean. $\mathrm{EC}_{50}$ and $\mathrm{IC}_{50}$ values were determined by fitting dose response data to a four parameter logistic equation using GraphPad Prism software (GraphPad Software, Inc.).

\section{Results}

A collection of 580 botanical extracts derived from Central Asian plants were tested for their effects on human adipocyte lipolysis and lipogenesis following the outline depicted in Figure 1. The extracts are unfractionated botanical mixtures and will serve as starting points to identify active components. The complexity of the mixtures dictated the use of a maximum concentration allowed by the assays to identify active extracts. High throughput primary human cell screening assays were developed for lipolysis and lipogenesis to identify both inhibitors and inducers in a single screen.

\subsection{Identification of botanical extracts with lipolytic inductive and suppressive properties in subcutaneous adipocytes}

All botanical extracts were examined for their acute lipolytic effect on human subcutaneous adipocytes in culture. To maximize signal to background and minimize the effect of FFA reuptake, the cells were exposed to the extracts for four hours prior to measuring free fatty acid release into the assay medium. The extract concentration was limited to $20 \mu \mathrm{g} / \mathrm{ml}$ to keep DMSO at or below $0.1 \%$ in the assay. Figure 2 shows the effects of each extract on 
FFA release as percent of the un-stimulated control (0.1\% DMSO). Most of the extracts had little effect, clustering around the vehicle control (100\%). However, 15 extracts were chosen for follow up studies because their activity was significantly above the screening cutoff value (3 standard deviations above the mean). The $\mathrm{Z}^{\prime}$ value (see Methods) for this screen was 0.503 , an acceptable value for initial screening.

\subsection{Partial lipolysis screen of botanical extracts in human omental cultured adipocytes}

Omental adiposity is linked to diabetes and metabolic disorders, suggesting that a screen using primary human omental adipocytes should be the most physiologically relevant system to identify novel actives. To determine the utility and overlap of a 384-well based omental adipocyte screen, half of the extracts were screened for their acute lipolytic effects using human omental adipocytes. After four hours of extract exposure, the amount of FFA released in the culture medium was determined. A similar number of active extracts were found using omental adipose derived cells as shown in Figure 3. Considerable overlap of active extracts was found in the omental screen and further characterization of the primary screen active extracts was performed. The $\mathrm{Z}^{\prime}$ value for the omental screen was determined to be 0.514 , on par with the primary subcutaneous adipocyte screen.

\subsection{Confirmation and dose dependence of lipolytic extracts in both subcutaneous and omental cells}

Fifteen extracts (2.6\%) from the subcutaneous cell and 8 extracts $(2.7 \%)$ from the omental cell screens showed an increase in lipolysis and were selected to determine if their primary activity could be confirmed. Human adipocytes were treated with 20 and $50 \mu \mathrm{g} / \mathrm{ml}$ of the botanical extracts for 4 hours and the amount of FFA released was determined. Additionally, the extracts were tested to determine if they interfered with the assay reagents to give a false positive signal by incubating them with the reagents alone. Only four of the 23 extracts selected for additional testing had their initial activity confirmed and were not observed to significantly interfere with the assay reagents or induce cytotoxicity (data not shown). The 4 identified extracts were KPL_00107E1, KPL_00248E12, KPL_00120E1, and UPL_00042E9. .

The four extracts were serially diluted to determine their dose response effect on adipocyte lipolysis in both subcutaneous and omental cells. Extract KPL_00120E1 displayed the largest increase in lipolysis and lowest $\mathrm{EC}_{50}$ in both subcutaneous and omental adipocytes (Table 1). The remaining extracts displayed dose dependent increases in lipolysis in both cell types compared to the vehicle control. Only KPL_00120E1 and KPL_00248E12 displayed $\mathrm{EC}_{50}$ values below $15 \mu \mathrm{g} / \mathrm{ml}$ and robust lipolysis without cytotoxicity. Three extracts were identified from the primary subcutaneous cell screen to inhibit basal lipolysis without inducing cytotoxicity; however, these extracts did not confirm their activity in follow up assays.

\subsection{Identification of botanical extracts with lipogenic properties using human primary subcutaneous preadipocytes}

The same 580 botanical extracts were tested for their effects on human subcutaneous adipocyte lipogenesis using partially differentiated adipocytes. Extracts were added to 1 week old partially differentiated ASCs and incubated with cells for 7 days. This second 7 day period is when differentiated adipocytes accumulate large amounts of triglyceride through lipogenesis. Extract concentrations of $50 \mu \mathrm{g} / \mathrm{ml}$ were used to maximize the response while limiting the cytotoxic effect of DMSO $(0.25 \%) .10 \mathrm{ng} / \mathrm{ml} \mathrm{TNFa}$ served as a positive control, inhibiting lipogenesis and triglyceride accumulation by $65 \%$ without cytotoxicity. Lipogenesis and cytotoxcity were determined for each extract in separate cell-based screens. Figure 4 shows the combined results of the two screens displaying triglyceride levels for 
both cytotoxic and noncytotoxic extracts. The lipogenesis screen gave a $Z^{\prime}=0.61 .44$ extracts (7.6\%) actively inhibited lipogenesis without inducing cytotoxicity and 2 induced lipogenesis. 14 of the initial actives from the primary screen were confirmed in a secondary inhibition assay and were retested in a dose response in subcutaneous and omental cells. Maximal inhibition of lipogenesis and induced cytotoxicity effects (and their $\mathrm{IC}_{50}$ concentrations) are shown for eight extracts in Table 2. Three extracts (KPL_00752E12, KPL_00752E7, and KPL_00752E4) displayed dose response inhibition of lipogenesis that was clearly separated from cytotoxicity effects. The two extracts that enhanced lipogenesis appear to contain free fatty acids and may have increased lipogenesis by increasing exogenous lipid concentration in the treatment medium.

\section{Discussion}

High throughput screening is the mainstay of drug discovery often relying on well-defined targets using miniaturized in vitro assays to allow rapid testing of hundreds of thousands of compounds. Cell-based activity assays also provide a robust screening system presenting the drug target in a more relevant context. These cell-based assay systems are typically constructed to enhance screening parameters while sacrificing the normal biological context of the target. One way to overcome this drawback is to use primary cells containing the target of interest. With recent advancements in human primary cell isolation and propagation, large numbers of high quality cells are readily available for drug discovery.

The current study demonstrates the potential of primary human ASC cultures to be used in primary compound or botanical screens. Specifically, we demonstrate that both undifferentiated and differentiated adipocyte cultures of primary human ASCs derived from subcutaneous and visceral/omental adipose depots can be used to efficiently screen botanical extracts in vitro. This indicates that the human primary ASC cultures can be adapted to a 384 well plate format and used as a robust alternative to murine pre-adipocyte cell lines such as 3T3-L1. Additionally, the use of a mixed donor lot can generate the billions of cells required for large screens and greatly reduce cell costs while averaging out the donor-todonor variability inherent in human primary cells.

While botanical extracts provide an available source of novel bioactive molecules, the use of unfractionated mixtures complicates primary screening. We have taken a systems approach by using human primary cell based assays to identify active extracts. This limits the bias of pre-selecting the target, however it adds complications of its own including possible cytotoxicity, cell impermeability, and metabolic activation of the extracts. Successful identification of active crude extracts requires a robust assay and can test the limits of a primary screen. Our results suggest human primary ASCs provide a relevant and robust primary cell based screening system. The primary and secondary screens of over 500 botanical extracts identified unique subsets with pro-lipolytic and anti-lipogenic activities that may eventually be useful in treating metabolic disorders.

The plant specimen collection used in this study contains a comprehensive sampling of Central Asia's (Kazakhstan, Kyrgyzstan, Tajikistan and Uzbekistan) plant biodiversity. Emphasis was placed on endemic plants and plants that either belong to families known for high natural product production or are known as local medicinal plants. In addition, plants of the same species were collected from various extreme environmental conditions under the premise that plants exposed to different stresses often contain different inducible natural products with different bioactivities. All collected samples are vouchered as herbarium specimens.

Two extracts with relatively potent lipolytic effects were identified in our screen and are derived from $A$. soongaricum, a relative of wolfsbane, and $C$. ochrolepidium, a relative of 
the common garden thistle. This Aconitum species is known to contain potent alkaloids with bioactive properties including immunological and antiarrhythmia activities. Recently, a root extract from another Aconitum species, A. carmichaeli Debeaux (Ranunculaceae), was found to have profound effects on the metabolic function of brown adipose tissue (BAT) in cold-stressed mice. The authors demonstrated that the extract enhanced UCP-1 gene expression and maintained the animal's core body temperature by increasing brown adipose tissue at the expense of white adipose. A similar induction of lipolysis to liberate fatty acids for fuel consumption may be occurring in the adipocytes treated with the A. soongaricum extract (KPL_00120E1). Likewise, the Cirsium ochrolepidium Juz. extract increased lipolysis in both subcutaneous and omental adipocytes (KPL_00248E12), however, extracts of this particular species have not been studied extensively. A different Cirsium species, $C$. oligophyllum, has been shown to contain bioactive components that activate lipolysis in cultured rat adipocytes. Additionally, oral administration of the extract reduced fat mass and overall body weight in the rats, increasing UCP-1 gene expression both in white adipose and brown adipose tissue. It is highly likely that a similar effect was identified in our screen from the Cirsium extract that we tested. The identification of these extracts from genera with known adipocyte activities further validates the utility of this screening system.

Three extracts from Acer negundo L. were found to have potent anti-lipogenic properties which did not represent aspects of cytotoxcity. These extracts were derived from different parts of the plant, with the leaf and above ground extracts showing more potency than the stem and twig extract. This species of maple has been found to contain flavonoids and other potentially bioactive compounds, however, extracts from A. negundo have not been studied for their effects on obesity. Another species of maple, A. tegmentosum, has been used in Korean traditional medicine to treat hepatic disorders including cirrhosis, hepatitis, and cancer. Some of these effects are attributed to the anti-inflammatory and antioxidant activities of some of the flavonoids found in the extracts. It seems likely that the A. negundo extracts may possess similar flavonoids that may be responsible for its ability to reduce lipogenesis. Several flavonoids have been found to inhibit lipogenesis in adipocytes and other cells through a variety of mechanisms including inhibiting fatty acid synthase or nuclear receptors. While we have not identified the active components of these extracts, there is reason to suspect similar bioactive components already known to inhibit adipocyte lipogenesis.

Subcutaneous and visceral adipose depots differ with respect to their cellular composition and expression of adipokines and pro-inflammatory growth factors. Their relative abundance is believed to play a contributory role to the pathogenesis of insulin resistance and the metabolic syndrome. Increased visceral adiposity, as compared to subcutaneous adiposity, has been correlated with the onset and severity of hyperglycemia, hypertriglyceridemia, and related co-morbidities of the metabolic syndrome. For these reasons, focusing on the use of visceral/omental derived rather than subcutaneous derived ASCs may have particular advantages as far as determining more precise pathophysiologic roles and may be more amenable for further development of drug discovery and botanical extract screening. In the current study, visceral ASCs were used in a limited primary screen and as a secondary counter-screen, however, they can be easily expanded and formatted for use in much larger primary screens. While their lipolytic responses were very similar, the lipogenic responses between omental and subcutaneous ASCs varied; however, the same trends were identified in both cell types.

Botanical extracts offer advantages and challenges both as adjunctive therapies and as a source of future pharmaceuticals. Plants serve as a rich source of diverse chemical compounds, i.e. bioactives, which, theoretically, can be extracted with appropriate methods, thereby reducing the cost of both discovery and manufacture. Coupling renewable botanical 
extracts with human primary cell screening technology represents a rapid and economical method to identify natural products that can become therapeutics.

\section{Acknowledgments}

Funding acknowledgements: Research supported by NIH Grant P50 AT002776-01 from the National Center for Complementary and Alternative Medicine (NCCAM) and Office of Dietary Supplements (ODS) which funds the Botanical Research Center; by Fogarty International Center of the National Institutes of Health under U01 TW006674 for the International Cooperative Biodiversity Groups; and NIH Grant R41 DK078399-01A1 from the National Institute for Diabetes and Digestive and Kidney Diseases.

\section{References}

1. Cefalu WT, Ye J, Zuberi A, Ribnicky DM, Raskin I, Liu Z, Wang ZQ, Brantley PJ, Howard L, Lefevre M. Botanicals and the metabolic syndrome. Am J Clin Nutr. 2008; 87:481S-7S. [PubMed: 18258643]

2. Ribnicky DM, Poulev A, Schmidt B, Cefalu WT, Raskin I. Evaluation of botanicals for improving human health. Am J Clin Nutr. 2008; 87:472S-5S. [PubMed: 18258641]

3. Cefalu WT, Brantley PJ. Botanicals and cardiometabolic risk: positioning science to address the hype. Metabolism. 2008; 57:S1-2. [PubMed: 18555847]

4. Floyd ZE, Wang ZQ, Kilroy G, Cefalu WT. Modulation of peroxisome proliferator-activated receptor gamma stability and transcriptional activity in adipocytes by resveratrol. Metabolism. 2008; 57:S32-8. [PubMed: 18555852]

5. Kirk H, Cefalu WT, Ribnicky D, Liu Z, Eilertsen KJ. Botanicals as epigenetic modulators for mechanisms contributing to development of metabolic syndrome. Metabolism. 2008; 57:S16-23. [PubMed: 18555849]

6. Schmidt B, Ribnicky DM, Poulev A, Logendra S, Cefalu WT, Raskin I. A natural history of botanical therapeutics. Metabolism. 2008; 57:S3-9. [PubMed: 18555851]

7. Stewart LK, Soileau JL, Ribnicky D, Wang ZQ, Raskin I, Poulev A, Majewski M, Cefalu WT, Gettys TW. Quercetin transiently increases energy expenditure but persistently decreases circulating markers of inflammation in C57BL/6J mice fed a high-fat diet. Metabolism. 2008; 57:S39-46. [PubMed: 18555853]

8. Wang ZQ, Ribnicky D, Zhang XH, Raskin I, Yu Y, Cefalu WT. Bioactives of Artemisia dracunculus L enhance cellular insulin signaling in primary human skeletal muscle culture. Metabolism. 2008; 57:S58-64. [PubMed: 18555856]

9. Yin J, Zuberi A, Gao Z, Liu D, Liu Z, Cefalu WT, Ye J. Effect of Shilianhua extract and its fractions on body weight of obese mice. Metabolism. 2008; 57:S47-51. [PubMed: 18555854]

10. Amini Z, Boyd B, Doucet J, Ribnicky DM, Stephens JM. St. John's Wort inhibits adipocyte differentiation and induces insulin resistance in adipocytes. Biochem Biophys Res Commun. 2009; 388:146-9. [PubMed: 19646953]

11. Chen WP, Ho BY, Lee CL, Lee CH, Pan TM. Red mold rice prevents the development of obesity, dyslipidemia and hyperinsulinemia induced by high-fat diet. Int J Obes (Lond). 2008; 32:1694704. [PubMed: 18794894]

12. Cornelius P, MacDougald OA, Lane MD. Regulation of adipocyte development. Annu Rev Nutr. 1994; 14:99-129. [PubMed: 7946535]

13. Green H, Kehinde O. An established preadipose cell line and its differentiation in culture. II. Factors affecting the adipose conversion. Cell. 1975; 5:19-27. [PubMed: 165899]

14. Green H, Kehinde O. Spontaneous heritable changes leading to increased adipose conversion in 3T3 cells. Cell. 1976; 7:105-13. [PubMed: 949738]

15. Green H, Kehinde O. Formation of normally differentiated subcutaneous fat pads by an established preadipose cell line. J Cell Physiol. 1979; 101:169-71. [PubMed: 541350]

16. Burris TP, Pelton PD, Zhou L, Osborne MC, Cryan E, Demarest KT. A novel method for analysis of nuclear receptor function at natural promoters: peroxisome proliferator-activated receptor gamma agonist actions on aP2 gene expression detected using branched DNA messenger RNA quantitation. Mol Endocrinol. 1999; 13:410-7. [PubMed: 10076998] 
17. Einstein M, Akiyama TE, Castriota GA, Wang CF, McKeever B, Mosley RT, Becker JW, Moller DE, Meinke PT, Wood HB, Berger JP. The differential interactions of peroxisome proliferatoractivated receptor gamma ligands with Tyr473 is a physical basis for their unique biological activities. Mol Pharmacol. 2008; 73:62-74. [PubMed: 17940191]

18. Fain JN, Buehrer B, Bahouth SW, Tichansky DS, Madan AK. Comparison of messenger RNA distribution for 60 proteins in fat cells vs the nonfat cells of human omental adipose tissue. Metabolism. 2008; 57:1005-15. [PubMed: 18555844]

19. Fain JN, Buehrer B, Tichansky DS, Madan AK. Regulation of adiponectin release and demonstration of adiponectin mRNA as well as release by the non-fat cells of human omental adipose tissue. Int J Obes (Lond). 2008; 32:429-35. [PubMed: 17895880]

20. Fain JN, Sacks HS, Buehrer B, Bahouth SW, Garrett E, Wolf RY, Carter RA, Tichansky DS, Madan AK. Identification of omentin mRNA in human epicardial adipose tissue: comparison to omentin in subcutaneous, internal mammary artery periadventitial and visceral abdominal depots. Int J Obes (Lond). 2008; 32:810-5. [PubMed: 18180782]

21. Gimble J, Guilak F. Adipose-derived adult stem cells: isolation, characterization, and differentiation potential. Cytotherapy. 2003; 5:362-9. [PubMed: 14578098]

22. Gimble JM, Katz AJ, Bunnell BA. Adipose-derived stem cells for regenerative medicine. Circ Res. 2007; 100:1249-60. [PubMed: 17495232]

23. Ort T, Arjona AA, MacDougall JR, Nelson PJ, Rothenberg ME, Wu F, Eisen A, Halvorsen YD. Recombinant human FIZZ3/resistin stimulates lipolysis in cultured human adipocytes, mouse adipose explants, and normal mice. Endocrinology. 2005; 146:2200-9. [PubMed: 15705777]

24. Bays HE, Gonzalez-Campoy JM, Bray GA, Kitabchi AE, Bergman DA, Schorr AB, Rodbard HW, Henry RR. Pathogenic potential of adipose tissue and metabolic consequences of adipocyte hypertrophy and increased visceral adiposity. Expert Rev Cardiovasc Ther. 2008; 6:343-68. [PubMed: 18327995]

25. Shen W, Punyanitya M, Chen J, Gallagher D, Albu J, Pi-Sunyer X, Lewis CE, Grunfeld C, Heymsfield SB, Heshka S. Visceral adipose tissue: relationships between single slice areas at different locations and obesity-related health risks. Int J Obes (Lond). 2007; 31:763-9. [PubMed: 17060927]

26. Halvorsen YD, Bond A, Sen A, Franklin DM, Lea-Currie YR, Sujkowski D, Ellis PN, Wilkison WO, Gimble JM. Thiazolidinediones and glucocorticoids synergistically induce differentiation of human adipose tissue stromal cells: biochemical, cellular, and molecular analysis. Metabolism. 2001; 50:407-13. [PubMed: 11288034]

27. Sen A, Lea-Currie YR, Sujkowska D, Franklin DM, Wilkison WO, Halvorsen YD, Gimble JM. Adipogenic potential of human adipose derived stromal cells from multiple donors is heterogeneous. J Cell Biochem. 2001; 81:312-9. [PubMed: 11241671]

28. McDonough PM, Agustin RM, Ingermanson RS, Loy PA, Buehrer BM, Nicoll JB, Prigozhina NL, Mikic I, Price JH. Quantification of lipid droplets and associated proteins in cellular models of obesity via high-content/high-throughput microscopy and automated image analysis. Assay Drug Dev Technol. 2009; 7:440-60. [PubMed: 19895345]

29. Zhang JH, Chung TD, Oldenburg KR. A Simple Statistical Parameter for Use in Evaluation and Validation of High Throughput Screening Assays. J Biomol Screen. 1999; 4:67-73. [PubMed: 10838414]

30. Raclot T, Oudart $\mathrm{H}$. Net release of individual fatty acids from white adipose tissue during lipolysis in vitro: evidence for selective fatty acid re-uptake. Biochem J. 2000; 348(Pt 1):129-36. [PubMed: 10794723]

31. Sui Y, Wu Z. Alternative statistical parameter for high-throughput screening assay quality assessment. J Biomol Screen. 2007; 12:229-34. [PubMed: 17218666]

32. Bray GA, Jablonski KA, Fujimoto WY, Barrett-Connor E, Haffner S, Hanson RL, Hill JO, Hubbard V, Kriska A, Stamm E, Pi-Sunyer FX. Relation of central adiposity and body mass index to the development of diabetes in the Diabetes Prevention Program. Am J Clin Nutr. 2008; 87:1212-8. [PubMed: 18469241] 
33. Fujimoto WY, Jablonski KA, Bray GA, Kriska A, Barrett-Connor E, Haffner S, Hanson R, Hill JO, Hubbard V, Stamm E, Pi-Sunyer FX. Body size and shape changes and the risk of diabetes in the diabetes prevention program. Diabetes. 2007; 56:1680-5. [PubMed: 17363740]

34. Lea-Currie YR, Duffin DJ, Buehrer BM. Use of adipose-derived stem cells in high-throughput screening to identify modulators of lipogenesis. Methods Mol Biol. 2011; 702:359-68. [PubMed: 21082415]

35. Gasparri F, Sola F, Bandiera T, Moll J, Galvani A. High-content analysis of kinase activity in cells. Comb Chem High Throughput Screen. 2008; 11:523-36. [PubMed: 18694389]

36. Minor LK. Label-free cell-based functional assays. Comb Chem High Throughput Screen. 2008; 11:573-80. [PubMed: 18694394]

37. Goldbard S. Bringing primary cells to mainstream drug development and drug testing. Curr Opin Drug Discov Devel. 2006; 9:110-6.

38. Koehn FE, Carter GT. The evolving role of natural products in drug discovery. Nat Rev Drug Discov. 2005; 4:206-20. [PubMed: 15729362]

39. Zhamierashvili MG, Tel'nov VA, Yunusov MS, Yunusov SY. Alkaloids of Aconitum soongaoricum. Khimiya Prirodnykh Soedinenii. 1980; 5:733-4.

40. Salimov BT, Turgunjov KK, Tashkhodzhaev B, Dzhakhangirov FN, Yunusov SY. Structure and antiarrhythmic activity of 12-acetyl-12-epinapelline, a new diterpenoid alkaloid from Aconitum soongaricum. Chemistry of Natural Compounds. 2004; 40:151-155.

41. Zhang J, Yang Y, Wang Y, Yao J, Ma R, Wei X. The study of medical plant - Aconitum soongaricum Stapf. Xibei Zhiwu Xuebao. 1999; 19:732-734.

42. Wei X, Zhang J, Wei B, Xie H, Ge X. Diterpenoid alkaloids from Aconitum soongaricum. Xibei Shifan Daxue Xuebao-Ziran Kexueban. 1998; 34:45-48.

43. Pigarevskii PV, Mokhnach IV. Immunomorphological changes in mouse lymphoid tissue as affected by Aconitum soongaricum Stapf., levamisole and sodium nucleinate. Doklady Akademii nauk SSSR. 1983; 268:754-756. [PubMed: 6600999]

44. Makino T, Kato K, Mizukami H. Processed aconite root prevents cold-stress-induced hypothermia and immuno-suppression in mice. Biol Pharm Bull. 2009; 32:1741-8. [PubMed: 19801837]

45. Mori S, Satou M, Kanazawa S, Yoshizuka N, Hase T, Tokimitsu I, Takema Y, Nishizawa Y, Yada T. Body fat mass reduction and up-regulation of uncoupling protein by novel lipolysis-promoting plant extract. Int J Biol Sci. 2009; 5:311-8. [PubMed: 19421341]

46. Aritomi M. Chemical Constituents in Aceraceous Plants. Ii. Flavonoid Constituents in Leaves of Acer Carpinifolium Siebold Et Zuccarini, A. Diabolicum Blume, A. Marmoratum Hara Form. Dissectum Rehder, and A. Negundo Linnaeus. Yakugaku Zasshi. 1964; 84:360-2. [PubMed: 14191448]

47. Backheet EY. Studies on the constituents of the leaves of Acer negundo (L.). Bulletin of Pharmaceutical Sciences, Assiut University. 2001; 24:1-6.

48. Backheet EY. Gallotannin and flavonoid glycosides from the stem bark of Acer negundo (L.). Bulletin of Pharmaceutical Sciences, Assiut University. 2003; 26:77-82.

49. Kupchan SM, Hemingway RJ, Knox JR, Barboutis SJ, Werner D, Barboutis MA. Tumor inhibitors. XXI. Active principles of Acer negundo and Cyclamen persicum. J Pharm Sci. 1967; 56:603-8. [PubMed: 6032773]

50. Kupchan SM, Takasugi M, Smith RM, Steyn PS. Tumor inhibitors. LXII. The structures of acerotin and acerocin, novel triterpene ester aglycones from the tumor inhibitory saponins of Acer negundo. J Org Chem. 1971; 36:1972-6. [PubMed: 5089340]

51. Yu T, Lee J, Lee YG, Byeon SE, Kim MH, Sohn EH, Lee YJ, Lee SG, Cho JY. In vitro and in vivo anti-inflammatory effects of ethanol extract from Acer tegmentosum. J Ethnopharmacol. 2010; 128:139-47. [PubMed: 20045722]

52. Tung NH, Ding Y, Kim SK, Bae K, Kim YH. Total peroxyl radical-scavenging capacity of the chemical components from the stems of Acer tegmentosum maxim. J Agric Food Chem. 2008; 56:10510-4. [PubMed: 18942844]

53. Park HJ, Della-Fera MA, Hausman DB, Rayalam S, Ambati S, Baile CA. Genistein inhibits differentiation of primary human adipocytes. J Nutr Biochem. 2009; 20:140-8. [PubMed: 18547799] 
54. Brusselmans K, Vrolix R, Verhoeven G, Swinnen JV. Induction of cancer cell apoptosis by flavonoids is associated with their ability to inhibit fatty acid synthase activity. J Biol Chem. 2005; 280:5636-45. [PubMed: 15533929]

55. Park HJ, Yang JY, Ambati S, Della-Fera MA, Hausman DB, Rayalam S, Baile CA. Combined effects of genistein, quercetin, and resveratrol in human and 3T3-L1 adipocytes. J Med Food. 2008; 11:773-83. [PubMed: 19053873] 


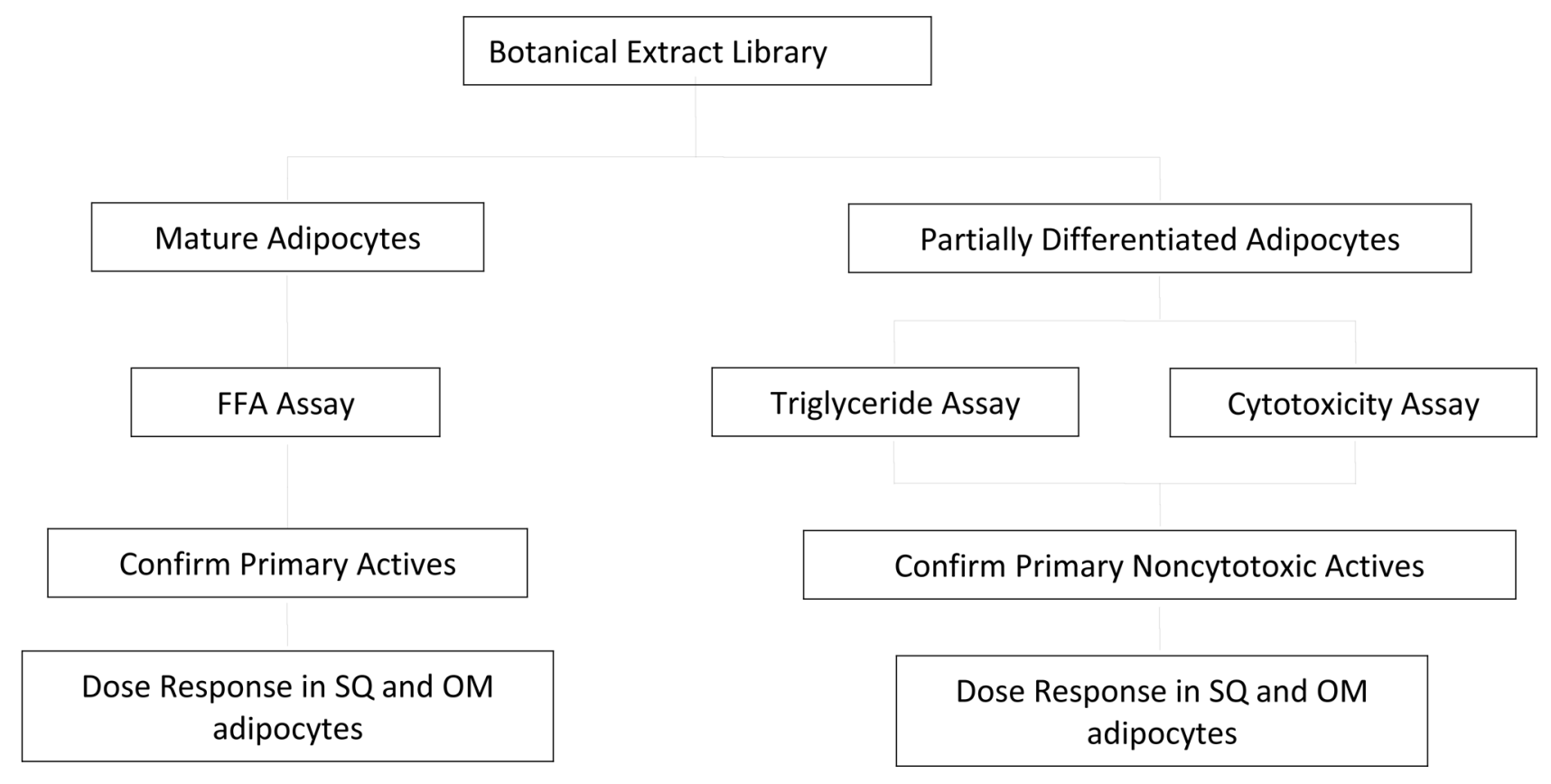

Figure 1.

Diagram of screening paradigm 


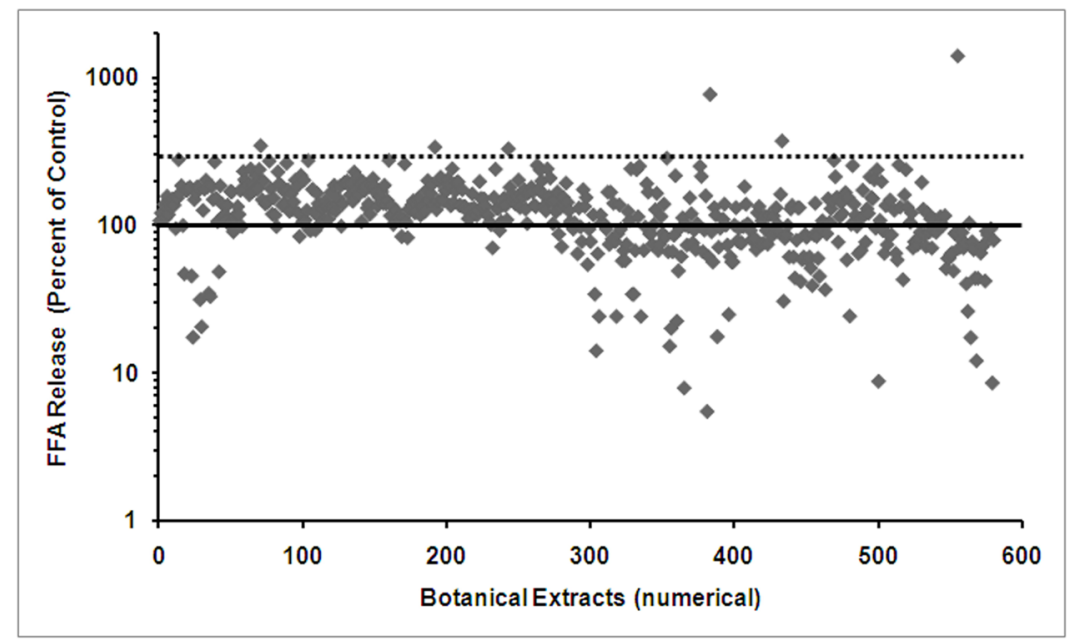

Figure 2.

Botanical extract lipolysis screen results using subcutaneous adipocytes. 580 botanical extracts were tested for their ability to induce fatty acid release. Values are shown as percent of the vehicle control $(0.1 \%$ DMSO). The solid line represents the vehicle control value for fatty acid release $(100 \%)$. The dashed line represents the screening cutoff value for active extracts: the overall mean $+/-$ three times the standard deviation. Extracts are represented by numerical progression on the $\mathrm{x}$-axis. The $\mathrm{y}$-axis is a log scale to contain the data range. Values are the mean of 4 replicates. 


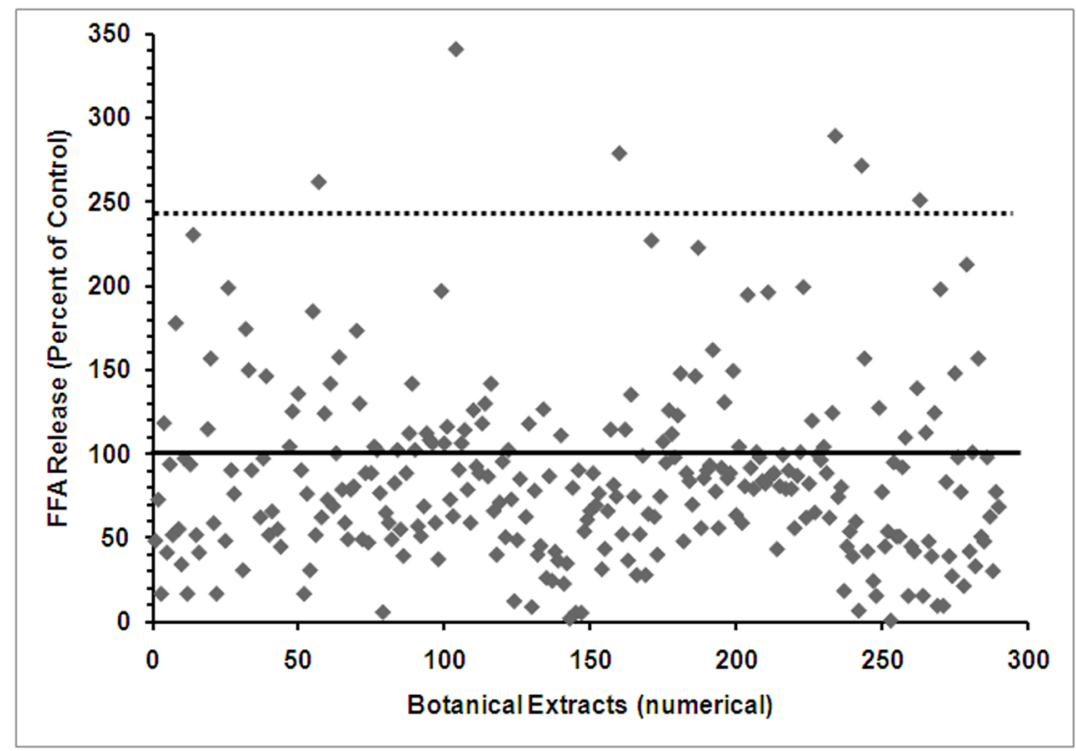

Figure 3.

Partial lipolysis screen results using omental adipocytes. A subset of the extracts were tested for their ability to induce fatty acid release in human omental adipocytes. Values and lines are as described for figure 2. The y-axis is linear. Values are the mean of 4 replicates. 


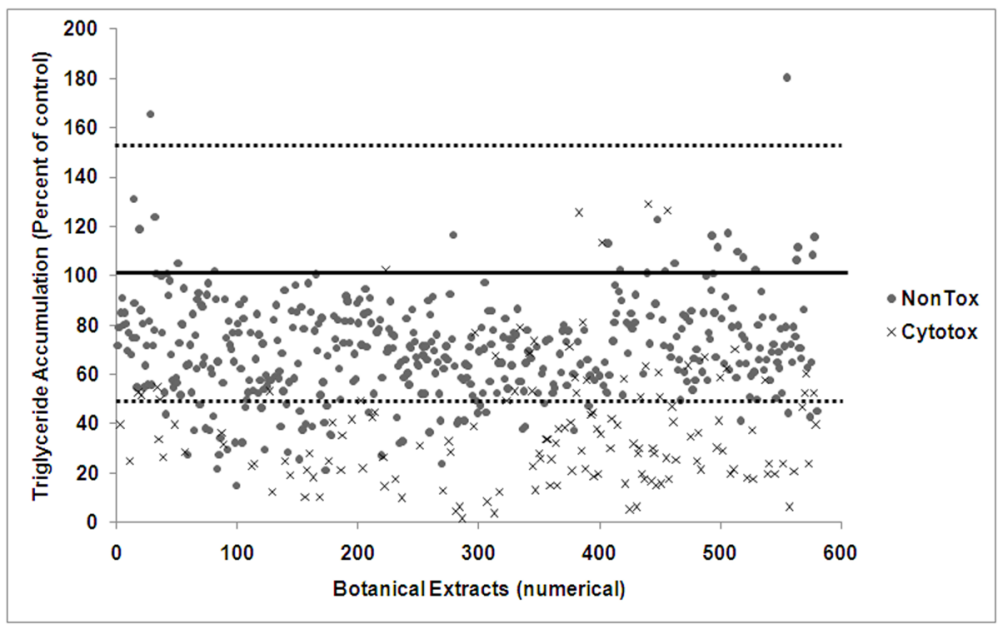

Figure 4.

Combined results of the lipogenic and cytotoxic effects of the botanical extracts. Values are displayed as percent of vehicle control for triglyceride accumulation. Extracts that showed cytotoxicity are represented by an "X", nontoxic extracts are represented by a filled circle. Values are the mean of 4 replicates. 
